\title{
Tyrophagus putrescentiae as Causative Agent of Wet Bubble Disease in Agaricus bisporus
}

\author{
Itisha*, Rachna Gulati, Manoj, Anita and Surjeet Singh \\ Department of Zoology, Chaudhary Charan Singh Haryana Agriculture University, \\ Hisar - 125004, Haryana, India \\ *Corresponding author
}

\section{A B S T R A C T}

Keywords

Agaricus bisporus,

Mycogone

perniciosa,

Tyrophagus

putrescentiae, Wet

bubble disease.

Article Info

Accepted:

10 September 2017

Available Online:

10 October 2017
A study was conducted to assess the role of Tyrophagus putrescentiae in dispersal of Mycogone perniciosa, a causative agent of wet bubble disease in Agaricus bisporus. T. putrescentiae started feeding as soon as they were released in $M$. perniciosa culture plates. A continuous significant increase in mite number was recorded at each observation period with peak (150.50 mites) after 20 days which was statistically comparable with 145.50 mites at 18 days. After 15 days, $10 \mathrm{~T}$. putrescentiae pairs were released from $M$. perniciosa infected plates to A. bisporus culture plates under aseptic conditions. After 6 days, whitish mouldy growth was started appearing on A. bisporus culture which soon spread to whole culture plate within 18 days. Mites were feeding and multiplying at this stage. The mite number significantly increased with increase in observation period on A. bisporus culture plates till $22^{\text {nd }}$ day. At this stage peak in the population was recorded (177.25 mites).

\section{Introduction}

Mushroom growing is one of the fastest growing and most technologically sophisticated horticultural industries in the world. Three species of edible mushroom, white button mushroom (Agaricus bisporus), paddy straw mushroom (Volvariella spp.) and oyster mushroom (Pleurotus sp.) are commercially grown in India. Button mushrooms are subject to a range of diseases and pests which have the capacity to cause serious crop losses. Sciarid fly, phorid fly, spring tails and mites are important arthropod pests of cultivated mushroom in India. Fifty four mite species have been found associated with mushrooms (Tripathi, 2005), out of which Tarsonemus myceliophagus Hussey, Tyrophagus lantneri Osb, Caloglyphus mycophagus (Megnin) (Kumar et al., 2004), Tyrophagus putrescentiae Schrank, Uroobovella sp. (Rana, 2008) are considered economically important pests.

Tyrophagus putrescentiae, commonly called as mould mite, copra mite or cheese mite, belong to the family Acaridae of the order Astigmata. Their small size makes early infestation by mites difficult to detect and enables them to enter packaging and exploit 
food residues in very small cracks and crevices. The life cycle consists of the egg, larva, protonymph, tritonymph, and adult stages. Development from the egg to adult takes about 1 to 3 weeks, and could take 118 days depending on environmental conditions and the food type on which the mite is reared (Kheradmand et al., 2007).

It is reported as an important vector of dispersing weed fungi throughout mushroom cultivation facilities (Okabe et al., 2001; Czajkowska, 2002). These include Fusariurm sp., Alternaria sp., Geotrichum sp., Mucor sp. and Trichophyton sp. Red pepper mites are also considered as vectors of Trichoderma and Hypocrea nigricans. The mites swarming on the casing and mushrooms bodies spread the spores of Trichoderma spp. (Hussey et al., 1969). Erban et al., (2016) studied the presence of Wolbachia, Cardinium, Bartonella, Blattabacterium and Solitalea in the eggs of $T$. putrescentiae which indicated mother to offspring (vertical) transmission. In white button mushroom, the incidence of wet bubble disease caused by the fungus, Mycogone perniciosa is a serious problem (Gahukar, 2014) whose carriers are presumed to be pests but no detailed study is available. It produces symptoms like dense white growth on gills; swollen stems and caps from which reddish-brown liquid oozes, chlorine like smell and crinkled, walnut-like bodies on the surface of the casing. T. putrescentiae can spread viruses causing diseases in mushrooms (Hussey et al., 1969) and are also responsible for the dispersal of weed and pathogenic fungal spores, so the present study has been undertaken to assess the role of Tyrophagus putrescentiae in wet bubble disease dispersal.

\section{Materials and Methods}

To assess the role of $T$. putrescentiae in transmission of wet bubble disease, culture of pathogenic fungi (Mycogone perniciosa) and
A. bisporus was reared on Potato Dextrose Agar (PDA) medium. Petriplates were inoculated with a bit of Mycogone perniciosa under Laminar flow. After five days of inoculation of $M$. perniciosa, 10 pairs of $T$. putrescentiae were released in plates under aseptic and penta-replicate conditions.

Experiments were conducted for 28 days at $27 \pm 1^{\circ} \mathrm{C}, 95-99$ percent relative humidity in the BOD incubator. Observations on mite feeding and multiplication were recorded after each alternative day. After 15 days, 10 pairs of $T$. putrescentiae were picked from $M$. perniciosa infected plates and released in $A$. bisporus culture ABL-2 plates. Observations on the $T$. putrescentiae population build up and development of whitish mouldy growth of mycelium on strain of A. bisporus was recorded to observe the transmission of disease. Counting of mites was done under the stereozoom microscope under 10X magnification.

\section{Statistical analysis}

Critical Difference (CD) was calculated for Tyrophagus putrescentiae population on fungi to see the effect of observation periods. The Software 'OPSTAT', developed at the Computer Centre, College of Basic Sciences and Humanities, CCS Haryana Agricultural University, Hisar, was used for the analysis.

\section{Results and Discussion}

The data pertaining to $T$. putrescentiae population build up on $M$. perniciosa is presented in Table 1. T. putrescentiae started feeding as soon as they were released in culture plates. Eggs were laid by $T$. putrescentiae, a continuous significant increase in number at each observation period $(\mathrm{CD}=6.62 ; \mathrm{p}=0.05)$. It was $28.00,35.00$, $61.00,71.75,84.75,101.75,115.50,129.25$, 145.50 mites and 150.50 at $2,4,6,8,10,12$, 
$14,16,18$ and 20 day. A peak in population (150.50 mites) was recorded after 20 days which was statistically comparable with 145.50 mites at 18 days. Thereafter, a gradual but significant decline in population was recorded with $137.25,123.75$ and 111.00 mites at 22, 24 and 26 day respectively.

After 15 days, $10 T$. putrescentiae pairs were released from $M$. perniciosa infected plates to A. bisporus culture plates under aseptic conditions. After 6 days, whitish mouldy growth was started appearing on A. bisporus culture (Plate I). It soon spread to whole culture plate within 18 days. Mites were feeding and multiplying at this stage (Plate
II). The colour of culture changed from pale brown to white. The statistical analysis showed significant effect of observation period on population buildup of $T$. putrescentiae on A. bisporus culture $(\mathrm{CD}=$ $6.73 ; \mathrm{p}=0.05)$ (Table 2). The mite number significantly increased with increase in observation period till $22^{\text {nd }}$ day. At this stage peak in the population was recorded (177.25 mites). Afterwards, it gradually declined to the lowest population count of 105.50 mites at 32 day. The mite count was statistically nonsignificant at zero and second day, $20^{\text {th }}$ and $26^{\text {th }}$ days, $18^{\text {th }}$ and $28^{\text {th }}$ days, $16^{\text {th }}$ and $30^{\text {th }}$ days. Mite number at $14^{\text {th }}$ and $32^{\text {nd }}$ days was also found to be at par with each other.

Table.1 Population of Tyrophagus putrescentiae on Mycogone perniciosa

\begin{tabular}{ll}
\hline $\begin{array}{l}\text { Observation (days after } \\
\text { release of mites) }\end{array}$ & $\begin{array}{l}\text { Mycogone perniciosa } \\
\text { Oy mite/ strain of }\end{array}$ \\
$\mathbf{2}$ & $20.00 \pm 0.00$ \\
$\mathbf{4}$ & $28.25 \pm 1.43$ \\
$\mathbf{6}$ & $35.00 \pm 1.78$ \\
$\mathbf{8}$ & $61.00 \pm 2.82$ \\
$\mathbf{1 0}$ & $71.75 \pm 4.55$ \\
$\mathbf{1 2}$ & $84.75 \pm 3.22$ \\
$\mathbf{1 4}$ & $101.75 \pm 1.93$ \\
$\mathbf{1 6}$ & $115.50 \pm 2.39$ \\
$\mathbf{1 8}$ & $129.25 \pm 1.93$ \\
$\mathbf{2 0}$ & $145.50 \pm 2.10$ \\
$\mathbf{2 2}$ & $150.50 \pm 1.44$ \\
$\mathbf{2 4}$ & $137.25 \pm 1.93$ \\
$\mathbf{2 6}$ & $123.75 \pm 1.88$ \\
\hline $\mathbf{S E}(\mathbf{m})$ & $111.00 \pm 2.34$ \\
\hline $\mathbf{C D}(\mathbf{p}=\mathbf{0 . 0 5})$ & $\mathbf{2 . 3 1}$ \\
\hline
\end{tabular}


Table.2 Population of Tyrophagus putrescentiae on Agaricus bisporus

\begin{tabular}{lll}
\hline $\begin{array}{l}\text { Observation (days } \\
\text { after release of mites) }\end{array}$ & $\begin{array}{l}\text { 10 pairs of mite/ strain of } \\
\text { Agaricus bisporus }\end{array}$ \\
\hline $\mathbf{0}$ & $20.00 \pm 0.00^{\mathrm{a}}$ \\
$\mathbf{2}$ & $26.00 \pm 0.81^{\mathrm{a}}$ \\
$\mathbf{4}$ & $37.25 \pm 1.54$ \\
$\mathbf{6}$ & $50.25 \pm 2.05$ \\
$\mathbf{8}$ & $62.50 \pm 1.75$ & \\
$\mathbf{1 0}$ & $74.00 \pm 2.48$ & \\
$\mathbf{1 2}$ & $89.25 \pm 1.54$ & \\
$\mathbf{1 4}$ & $102.75 \pm 1.93^{\mathrm{e}}$ \\
$\mathbf{1 6}$ & $113.50 \pm 2.95^{\mathrm{d}}$ \\
$\mathbf{1 8}$ & $129.50 \pm 3.12^{\mathrm{c}}$ \\
$\mathbf{2 0}$ & $150.50 \pm 1.70^{\mathrm{b}}$ \\
$\mathbf{2 2}$ & $177.25 \pm 2.21$ \\
$\mathbf{2 4}$ & $164.50 \pm 2.10$ \\
$\mathbf{2 6}$ & $152.25 \pm 1.79^{\mathrm{b}}$ \\
$\mathbf{2 8}$ & $131.25 \pm 3.70^{\mathrm{c}}$ \\
$\mathbf{3 0}$ & $118.75 \pm 3.35^{\mathrm{d}}$ \\
$\mathbf{3 2}$ & $105.50 \pm 3.66^{\mathrm{e}}$ \\
\hline SE(m) & $\mathbf{2 . 3 6}$ \\
\hline CD(p $=\mathbf{0 . 0 5})$ & $\mathbf{6 . 7 3}$ \\
\hline
\end{tabular}

Plate.1 Appearance of wet bubble disease on A. bisporus Plate II: Spreading of wet bubble disease

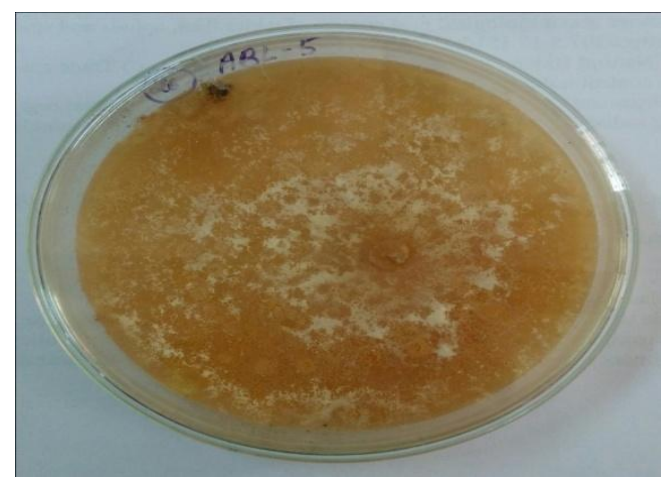

Most of the mites feed on wild fungus (contaminants in cultivated mushrooms) and help in dispersal of their spores (Price, 1976). Wild fungi act as competitive fungi in cultivated mushroom beds thus affecting the overall yield (Okabe, 1999). The life cycle of $C$. cinerea along with the mite $T$. putrescentiae starts with the mite feeding on the mushroom tissues including the spores (González, 2008).

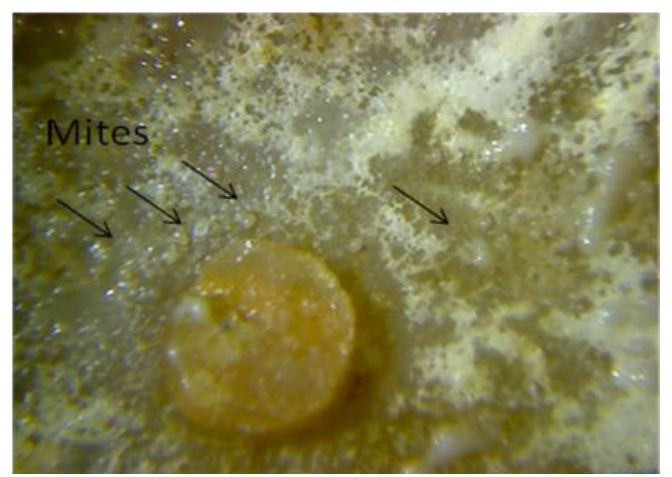

In nature, the spores of coprophilous fungi survive their passage through the animal digestive system when consumed by herbivorous (Richardson, 2001). Basidiospores ingested by the mites will not be digested. Faecal pellets containing a number of fungal spores are formed and excreted. The spores in the faecal pellets easily germinate and form colonies. Mites can affect fungi by grazing, and 
they may be integrally involved in the dominance of mycotoxigenic fungal species due to their role in dispersal of fungal spores and also influenced the increase of aflatoxin production from the fungus (Franzolin et al., 1999; Hubert et al., 2003).

In the present study, results showed that $T$. putrescentiae act as carrier of wet bubble disease. T. putrescentiae started feeding as soon as they were released in culture plates of $M$. perniciosa. The colour of culture changed from pale brown to white. In white button mushroom, white bubble disease, caused by Mycogone perniciosa (Magnus) hampers the yield (Gahukar, 2014). Krantz (1978) earlier reported that mites collected from infested cultures were Tyrophagus putrescentiae. The mites are found in environments suitable also for fungi, particularly environments with high humidity and elevated temperatures (Sánchez-Ramos et al., 2007). Since $T$. putrescentiae transfers fungal spores to food, another common name was given as mold mite (Hubert et al., 2004).

In addition to $T$. putrescentiae, few more mite species like Trochometridium, (Lindquist, 1985), Siteroptes cerealium (Suski, 1973), Tarsonemus ips (Moser, 1985), Imparipes haeseleri, I. apicola and I. breganti (Ebermann and Hall, 2003) feeds on fungi and help in transportation of fungal spores. In all cases, only females were responsible for fungal transfer. Although there is no data concerning the viability of the spores transported in the sporotheca, mites might act as fungi spreaders transporting spores inside or outside their bodies to other possible substrates, rewarded at the same time by being provided with mycelia for a new colony of mites (Ramírez-Suárez et al., 2002). Eggs were laid among the faecal pellets, indicating that fungi play an important role in the mites' cycle of development (Ebermann and Hall, 2003). Upon germination of fungal mycelium from the basidiospores, hatching larvae are supplied directly with food for their further development. Gazeta et al., (2012) recorded an association between $T$. putrescentiae and pathogenic bacteria such as
Klebsiella sp., Pseudomonas aeruginosa, Staphylococcus aureus and Candida albicans. When agar plates were infested with mites, 100 percent bacterial colonies developed. Considering the role of $T$. putrescentiae as vector for $M$. perniciosa causing wet bubble disease in A. bisporus spawn, further research is needed to understand the ecology of this organisms.

\section{References}

Czajkowska, B., 2002. Development of acarid mites on Fusarium oxysporum. Bull. Polish Acad. Sci., Biological Sciences, 5: 37-48.

Ebermann, E., and Hall, M. 2003. First record of sporothecae within the mite family Scutacaridae (Acari, Tarsonemina). Zoologischer Anzeiger, 242: 367-375.

Erban, T., Rybanska, D., Harant, K., Hortova, B. and Hubert, J. 2016. Feces derived allergens of Tyrophagus putrescentiae reared on dried dog food and evidence of the strong nutritional interaction between the mite and Bacillus cereus producing protease bacillolysins and exo-chitinases. Front. Physiology, 7: 53.

Franzolin, M.R., Gambale, W., Cuero, R.G., Correa, B., 1999. Interaction between toxigenic Aspergillus flavus Link and mites (Tyrophagus putrescentiae (Schrank)) on maize grains: effects on fungal growth and aflatoxin production. Journal of Stored Products Research, 35: 215-224.

Gahukar, R.T., 2014. Mushroom pest and disease management using plant-derived products in the Tropics: A Review, International Journal of Vegetable Sciences, 20: 78-88.

Gazeta, G.S., Norberg, A.N., Aboud-Dutra, A.E. and Serra-Freire, N.M. 2012. Tyrophagus putrescentiae (Schrank, 1781) as a vector of pathogenic bacteria: laboratory observation. Entomologia $y$ Vectores, 7:49-55.

González, M.N., 2008. Growth, fruiting body 
development and laccase production of selected coprini. Dissertation zur Erlangung des Doktorgrades der Mathematisch Naturwissenschaftlichen Fakultäten der Georg-August-Universität, Göttingen, 1-227 pp.

Hubert, J., Jarosik, V., Mourek, J., Kubatova, A. and Zdarkova, E. 2004. Astigmatid mite growth and fungi preference (Acari: Acaridida): Comparisons in laboratory experiments. Pedobiologia, 48: 205-214.

Hubert, J., Stejskal, V., Munzbergova, Z., Kubatova, A., Vanova, M., and Zdarkova, E. 2003. Mites and fungi in heavily infested stores in the Czech Republic. Journal of Economic Entomology, 97 : 2144-2153.

Hussey, N.W., Read, W.H. and Hesling, J.J. 1969. The Pests of Protected Cultivation. Edward Arnold Press, London, 404 pp.

Kheradmand, K., Kamali, K., Fathipour, Y. and. Goltapeh, E.M. 2007. Development, life table and thermal requirement of Tyrophagus putrescentiae (Astigmata: Acaridae) on mushrooms. Journal of Stored Products Research, 43(3): 276281.

Krantz, G.W., 1978. A manual of acarology. O.S.U. Book stores Ltd., Corvallis, Oregon, USA.

Kumar, S., Gautam, Y. and Sharma, S.R. 2004. Mushroom mites and their management. Mushroom Research, 13(2): 46-52

Moser, J.C., 1985. Use of sporothecae by phoretic Tarsonemus mites to transport ascospores of Coniferous bluestan fungi. Trands in Britain Mycology Society, 84: 750-753.

Okabe, K., 1999. Vectoring of Hypocrea nigicans (Hypocreales: Hypocreaceae) by three fungivorus mite species (Acari: Acaridae). Experimental and Applied
Acarology, 23(8): 860-0862.

Okabe, K., Miyazaki, K. and Yamamoto, H. 2001. Population increase in mushroom pest mites on cultivated Hypsozygus marmoreus and their vectoring of weed fungi between mushroom cultivation media. Japan Journal of Applied Entomology and Zoology, 45(2): 75-81.

Price, D.W., 1976. Passage of veriticillum allogram populars through the alimentary canal of the mites. Phytopathology, 66: 46-50.

Ramírez-Suárez, A., Zavaleta-Mejía, E., Kawasoe, S.O., Sánchez, G.M.C. and Valdéz, C.J. 2002. A possible role for Rhizoglyphus robustus Nesbitt (Astigmata: Acaridae) in transmission of Sclerotium cepivorum Berk. (Deuteromycetes: Mycelia-Sterilia). Applied Entomology Zoology, 37: 663669.

Rana, M., 2008. Studies on abundance and damaging potential of Acarine species on mushroom. M.Sc. Thesis, CCS Haryana Agriculture University, Hisar.

Richardson, M. J., 2001. Diversity and occurrence of coprophilous fungi. Mycology Research, 105: 387-402.

Sánchez-Ramos, I., Álvarez-Alfageme, F. and Castañera, P. 2007. Effects of relative humidity on development, fecundity and survival of three storage mites. Experimental and Applied Acarology, 41: 87-100.

Suski, Z.W., 1973. A revision of the Siteroptes cerealium (Kirchner) complex (Acarina: Heterostigmata, Pyemotidae). Annal Zoology, 30: 509-535.

Tripathi, D.P., 2005. Mushroom Cultivation, Oxford, IBH Publishing Co. Pvt. Ltd., New Delhi., p.352.

\section{How to cite this article:}

Itisha, Rachna Gulati, Manoj, Anita and Surjeet Singh. 2017. Tyrophagus putrescentiae as Causative Agent of Wet Bubble Disease in Agaricus bisporus. Int.J.Curr.Microbiol.App.Sci. 6(10): 1172-1177. doi: https://doi.org/10.20546/ijcmas.2017.610.141 